\title{
Gênero e distribuição espacial da população no oeste do Paraná ${ }^{1}$
}

Lucir Reinaldo Alves

Centro de Ciências Sociais e Aplicadas da Universidade Estadual do Oeste do Paraná (UNIOESTE/Campus Toledo)

Jandir Ferrera de Lima

Programa de Pós-Graduação em Desenvolvimento Regional e Agronegócio da Universidade Estadual do Oeste do Paraná (UNIOESTE/Campus de Toledo)

Ricardo Rippel

Programa de Pós-Graduação em Desenvolvimento Regional e Agronegócio da Universidade Estadual do Oeste do Paraná (UNIOESTE/Campus de Toledo)

Moacir Piffer

Programa de Pós-Graduação em Desenvolvimento Regional e Agronegócio da Universidade Estadual do Oeste do Paraná (UNIOESTE/Campus de Toledo)

Recebido: 18/10/2012 Versão revisada (entregue): 18/03/2013 Aprovado: 24/03/2013

\section{Resumo}

Neste artigo analisa-se o perfil da localização e distribuição espacial da população masculina e feminina no oeste do Paraná. Os dados de população coletados pelo Instituto Brasileiro de Geografia e Estatística (IBGE) foram desagrupados em quatro variáveis: população urbana feminina, população rural feminina, população urbana masculina e população rural masculina, distribuídos nos cinquenta municípios que compõem a Região. O período estudado abrangeu os anos de 2000 e 2010. Os dados foram analisados a partir de alguns indicadores de localização consagrados pela análise regional. Os resultados mostraram que Cascavel, Foz do Iguaçu e Toledo possuem uma população urbana masculina e feminina mais numerosa que os demais municípios. Já os demais municípios estão consolidando suas economias, seja na transformação agroalimentar, seja na prestação de serviços, fato que se reflete em uma maior participação da população urbana, que cresce mais rapidamente em relação a população rural.

Palavras-chave | Distribuição espacial da população; gênero; oeste do Paraná; região.

Código JEL | J16; R12; 018.

\footnotetext{
${ }^{1}$ Uma versão preliminar desse texto foi apresentada no I Seminário de Desenvolvimento Regional, Estado e Sociedade, realizado em 2012 no IPPUR/UFRJ. O texto é baseado em pesquisa financiada pela Fundação Araucária e pelo Conselho Nacional de Desenvolvimento Cientifico e Tecnológico (CNPq).
} 


\title{
GENDER AND SPATIAL DISTRIBUTION OF POPULATION IN WESTERN PARANÁ
}

\begin{abstract}
This paper analyzes the profile of the location and spatial distribution of male and female population in Western Paraná. Population data collected by the Brazilian Institute of Geography and Statistics (IBGE) were grouped into four variables: urban female population, rural female population, urban male population and rural male population, distributed in the fifty municipalities that comprise the region. The periods studied are the years of 2000 and 2010. Data were analyzed from some location indicators established by the regional analysis. The results showed that Cascavel, Foz do Iguaçu and Toledo have a male and female urban population larger than the other municipalities. The other municipalities are consolidating their economies, whether in agri-food processing or provision of services, a fact that is reflected in a higher share of urban population, which grows more rapidly in relation to the rural population.
\end{abstract}

Keywords | Spatial distribution of population; gender; Western Paraná; region.

JEL-Code | J16; R12; 018.

\section{GÉNERO Y DISTRIBUCIÓN ESPACIAL DE LA POBLACIÓN EN EL OESTE DE PARANÁ}

\section{Resumen}

En este trabajo se analiza el perfil de ubicación y distribución espacial de la población masculina y femenina en el oeste de Paraná. Los datos de población recogidos por el Instituto Brasileño de Geografía y Estadística (IBGE) fueron clasificados de acuerdo a cuatro variables: población urbana femenina, población rural femenina, población urbana masculina y población rural masculina, distribuidos en los cincuenta municipios que componen la Región. El período estudiado es de 2000 a 2010. Los datos fueron analizados a partir de algunos indicadores de localización consolidados por el análisis regional. Los resultados mostraron que los municipios de Cascabel, Foz de Iguazú y Toledo tienen una población urbana masculina y femenina más numerosa que los otros municipios. Por otro lado, los otros municipios, que están consolidando sus economías, a través de la industria de procesamiento de alimentos y la prestación de servicios, demuestran una mayor proporción de población urbana que crece más rápidamente que la población rural.

Palabras-clave | Distribución espacial de la población; género; Oeste de Paraná; región.

Código JEL | J16; R12; 018.

\section{Introdução}

Na evolução histórica e populacional do oeste paranaense destacam-se algumas etapas. A primeira delas é a da ocupação territorial e da expansão demográfica. Essa etapa vai de 1940 a 1970, um período que marca a Região com expressivo movimento imigrante e o estímulo a altas taxas de incremento populacional. Essa expansão e essa atratividade de população estimularam o crescimento tanto das áreas rurais quanto das urbanas. Nessa época, a despeito da significativa 
capacidade demonstrada pelos centros urbanos da Região em absorverem amplos contingentes de população egressa do meio rural, o seu conjunto de municípios apresentou saldos migratórios negativos (RIPPEL, 2005).

Já a segunda etapa, que vai de 1975 a 1990, marca a saturação do processo de ocupação territorial. Nessa fase, esgota-se a absorção de imigrantes nas áreas rurais, apesar do setor primário da economia regional continuar dinâmico. Até 1970, a população regional ainda era predominantemente rural e chega a 1980 com participação percentual no total da população regional praticamente equivalente ao percentual urbano. Porém, de 1980 a 1990, ocorre um movimento de forte emigração do rural para o urbano, estimulada pela conformação dos polos econômicos de Curitiba, Londrina e Maringá, no estado do Paraná. Também outros polos nos estados do Rio Grande do Sul, Santa Catarina e São Paulo absorveram, sucessivamente, vastas quantidades de indivíduos anteriormente residentes no oeste paranaense.

As alterações na estrutura agrícola da Região promoveram o esvaziamento demográfico rural e a expansão da rede urbana. O rápido crescimento da atividade agrícola, que se ampliou rapidamente e proporcionou renda e expansão dinâmica do comércio, foi acompanhado, nas décadas de 1980 e 1990, pelo surgimento e crescimento das cidades e das agroindústrias cooperativas. Nesse período, o oeste do Paraná caracterizava-se como essencialmente agrícola. A partir de então, a indústria local passou a se consolidar e ter sua dinâmica orientada pelo comportamento da transformação agroalimentar.

A terceira etapa, que vai de 1990 até nossos dias, aqui nomeada de "maturidade", é marcada pela estabilidade nos fluxos migratórios externos à Região, bem como o estabelecimento de critérios mais elevados de qualificação pessoal para absorção e inserção de migrantes (RIPPEL, 2005).

Frente a essa realidade, poucos estudos evidenciam a situação do gênero e da localização da população na região oeste. Cunha (2003a) e Piffer (1999) sustentam que a análise do oeste do Paraná fornece um cenário interpretativo do processo pelo qual a migração se entrelaça com fatores econômicos, acelera ou retarda o desenvolvimento e, também, estimula a difusão das atividades de base econômica ao longo do espaço econômico regional. Por isso, esse artigo analisa o perfil da localização e distribuição da população masculina e feminina no espaço geográfico do oeste do Paraná no primeiro decênio do século XXI.

\section{Procedimentos metodológicos}

O período estudado foi a etapa de saturação e de maturidade dos fluxos migratórios. Dessa maneira, a periodização oferece certa estabilidade para a análise 
e interpretação das informações. Os anos de coleta das informações foram 2000 e 2010 .

Mapa 1 - Mesorregião oeste do Paraná, Brasil

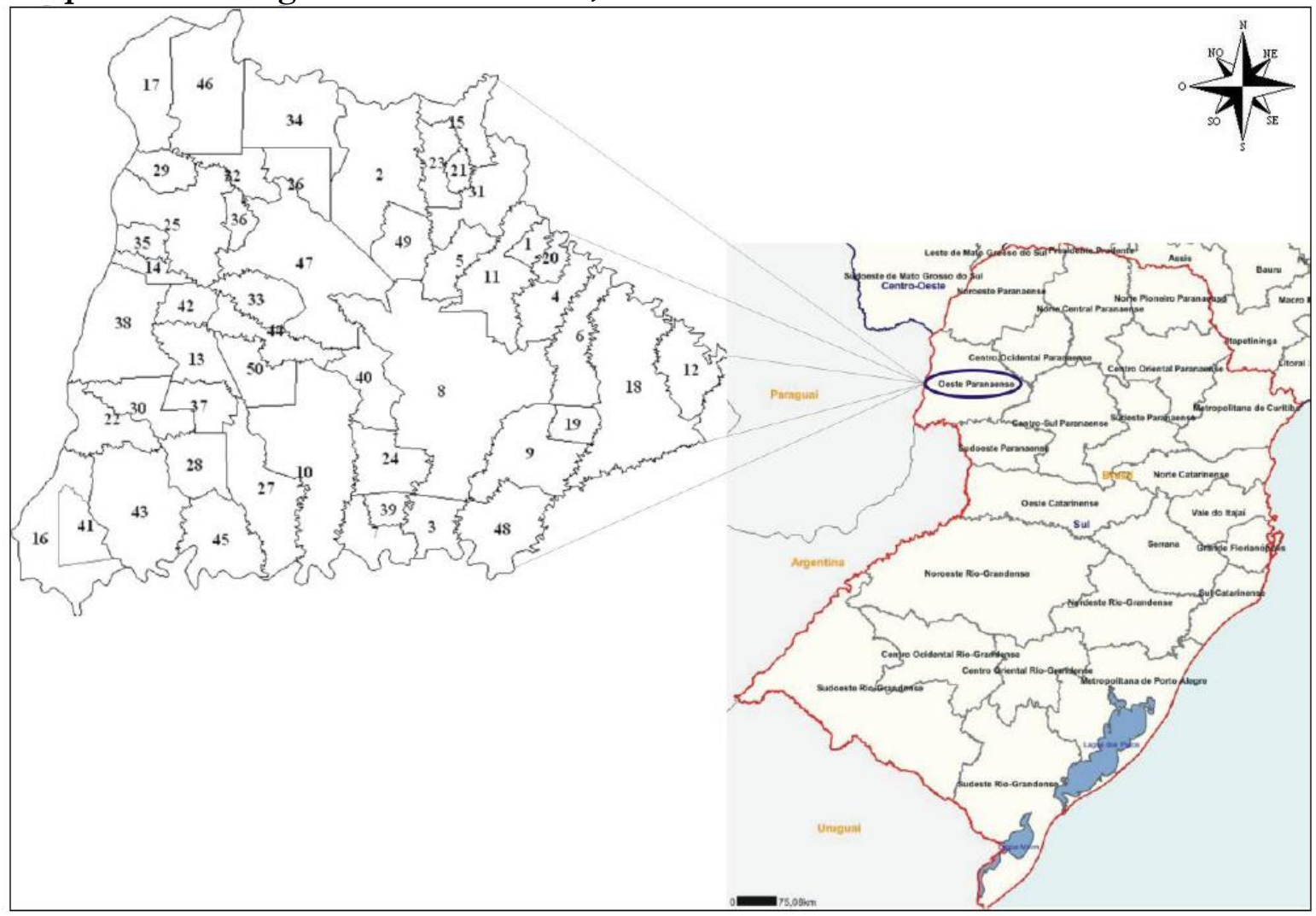

Fonte: IBGE (2012).

Os dados de população foram desagrupados em quatro variáveis: população urbana feminina, população rural feminina, população urbana masculina e população rural masculina, a partir dos resultados dos Censos Demográficos do Instituto Brasileiro de Geografia e Estatística (IBGE), e desagrupados nos cinquenta municípios que formam o oeste do Paraná (Mapa 1). Os dados foram analisados a partir dos indicadores de localização, tradicionais nos estudos de analise regional quantitativa, quais sejam:

Quociente Locacional (QL): nesse estudo, ele mostrou a importância de cada variável de população em relação à população total de cada município.

O QL é o indicador de análise regional mais difundido no meio acadêmico e demonstra o comportamento locacional de cada variável. Ele é uma medida de natureza descritiva que caracteriza os vários setores e as diferentes regiões em análise, do ponto de vista do nível de especialização/diversificação das suas estruturas produtivas. $\mathrm{O}$ QL utiliza valores relativos como parâmetro de distribuição da variável entre os ramos de atividade econômicos. Essa característica anula o efeito "tamanho" das regiões, permitindo a estimativa de 
indicadores confiáveis. (PUMAIN; SAINT-JULIEN, 1997; DELGADO; GODINHO, 2002; PIACENTI; FERRERA DE LIMA, 2012). Assim, o QL possui uma natureza setorial, pois se preocupa com a localização da variável base (população) entre os municípios. A equação (1) expressa o cálculo do QL.

$$
\mathrm{QL}=\frac{\text { População do tipo i no município j / População do tipo i no oeste do PR }}{\text { População total do município j / População total do oeste do PR }}
$$

Dessa forma, o QL compara a participação percentual da população por tipo de um município j com a participação percentual do oeste do PR. A importância do município $j$ no contexto regional, em relação a variável $x$ estudada, é demonstrada quando o QL assume valores acima da unidade. Nesse caso (quando o QL for maior ou igual à unidade), indica a representatividade da variável $x$ em um município $j$ específico, ou seja, indica que esse tipo de população tem maior importância relativa nesse município. O contrário ocorre quando o QL for menor que a unidade.

Coeficiente de Localização: identificou dentre as variáveis utilizadas quais são mais concentradas espacialmente em cada ano analisado na região.

O Coeficiente de Localização é o somatório, para todos os municípios, da participação percentual da população do tipo $i$ do município $j$ sobre a região de referência, menos a participação percentual total do município $j$ sobre a região de referência, dividido por dois. Esse coeficiente varia entre zero e um e permite identificar o grau de dispersão relativa das variáveis estudadas e selecionar aquelas que, presumivelmente, teriam menor tendência à concentração espacial.

$$
C L=\frac{\left(\left|j^{e i}-\sum_{i} j^{e i}\right|\right)}{2}
$$

Quanto mais próximo de zero a população do tipo $i$ estará distribuída regionalmente da mesma forma semelhante ao conjunto de todos os tipos de população de cada município. Ou seja, esse coeficiente se utiliza da participação dos municípios nas diversas variáveis e parte do princípio de que cada variável poderá ter uma participação semelhante ao que o total do município possui sobre a região de referência. As populações do tipo $i$ que se aproximarem da unidade são as que possuem distribuição diferenciada. Logo, classificam-se os diferentes tipos de população em mais distribuídos (próximos a zero), com uma concentração 
intermediária (com CL médio), e os tipos muito concentrados (mais próximos de um).

Coeficiente de Redistribuição: Esse indicador foi utilizado para verificar se houve dispersão ou concentração espacial das variáveis de população no período.

O coeficiente de redistribuição foi utilizado para demonstrar os tipos de população que se concentraram mais ou que, pelo contrário, se dispersaram mais entre os municípios do Oeste do Paraná no período de 2000 a 2010. O valor do coeficiente oscila entre 0 e 1 . Quanto mais da unidade forem os resultados do coeficiente, mas poder-se-á concluir que, no período de análise, ocorreram mudanças no padrão de localização de cada tipo de população. Se for próximo a 0 , terá ocorrido o contrário.

$$
C R=\frac{\sum_{j}(|j e i-j e i|)}{2}
$$

Sendo que:

CR = Coeficiente de Redistribuição

$\sum \mathrm{j}=$ Somatório dos municípios para a população do tipo $i$

$\mathrm{j}^{\mathrm{e}}=$ Distribuição percentual da população do tipo $i$ entre os municípios no ano inicial ( $\mathrm{t} 0$ ) e ano final (t1)

Coeficiente de Reestruturação: foi utilizado para verificar se houve nos municípios mudança na importância relativa que cada gênero detinha no total da população. Os seus resultados ajudaram a perceber qual gênero ganhou ou perdeu importância regionalmente.

O Coeficiente de Reestruturação é expresso pela equação:

$$
C T_{j}=\frac{\sum_{i}\left|I_{1}-I_{0}\right|}{2}
$$

Em que:

$C T_{j}=$ Quociente de Reestruturação no município j

$\sum_{\mathrm{i}}=$ Somatório dos tipos de população no município $j$

$\mathrm{I}_{0}=$ Distribuição percentual da população do tipo $i$ inicial no município $j$

$\mathrm{I}_{1}=$ Distribuição percentual da população do tipo $i$ final no município $j$ 


\section{A população do oeste do Paraná na fase da maturidade migratória}

Como já mencionado na Introdução, a década de 1990 configurou o início do estágio de maturidade da dinâmica demográfica do oeste paranaense. Essa fase é marcada por uma leve recuperação do ritmo de crescimento populacional, condicionada pelo declínio acentuado do ímpeto emigratório da área. A estimativa preliminar de saldo migratório do oeste do Paraná nos anos 1990 evidenciou um resultado ainda negativo, indicativo de perda líquida populacional, porém baixo em função do aumento no volume da imigração.

No âmbito intrarregional, passaram a prevalecer, ao final do século XX, os deslocamentos intermunicipais, notando-se um aumento substantivo da participação percentual dos municípios de Cascavel, de Toledo e de Foz do Iguaçu no conjunto das trocas migratórias desse tipo na Região. $\mathrm{O}$ oeste paranaense absorveu grandes levas de migrantes ligadas ao campo, cumprindo um papel importante no processo de redistribuição espacial da população nacional e estadual. Não ocorreu apenas a redução do ímpeto migratório para a área, mas também mudanças nas formas de inserção dos migrantes, que se refletiram na urbanização e na grande desarticulação das formas de ocupação do território (RIPPEL, 2005).

Analisando-se as informações de domicilio da população da Região, vê-se que em 1970 aproximadamente $80 \%$ da população residia nas zonas rurais. Trinta anos depois, em 2000, apenas 18\% do total populacional regional residia ainda no campo (vide Figura 1). Além disso, a evolução da população urbana é cada vez mais significativa em relação à retração da população rural, demonstrando que as áreas urbanas do oeste paranaense também são atrativas em relação à outras regiões. 
Figura 1 - Oeste do Paraná: evolução da população segundo situação de domicílio, 19702010

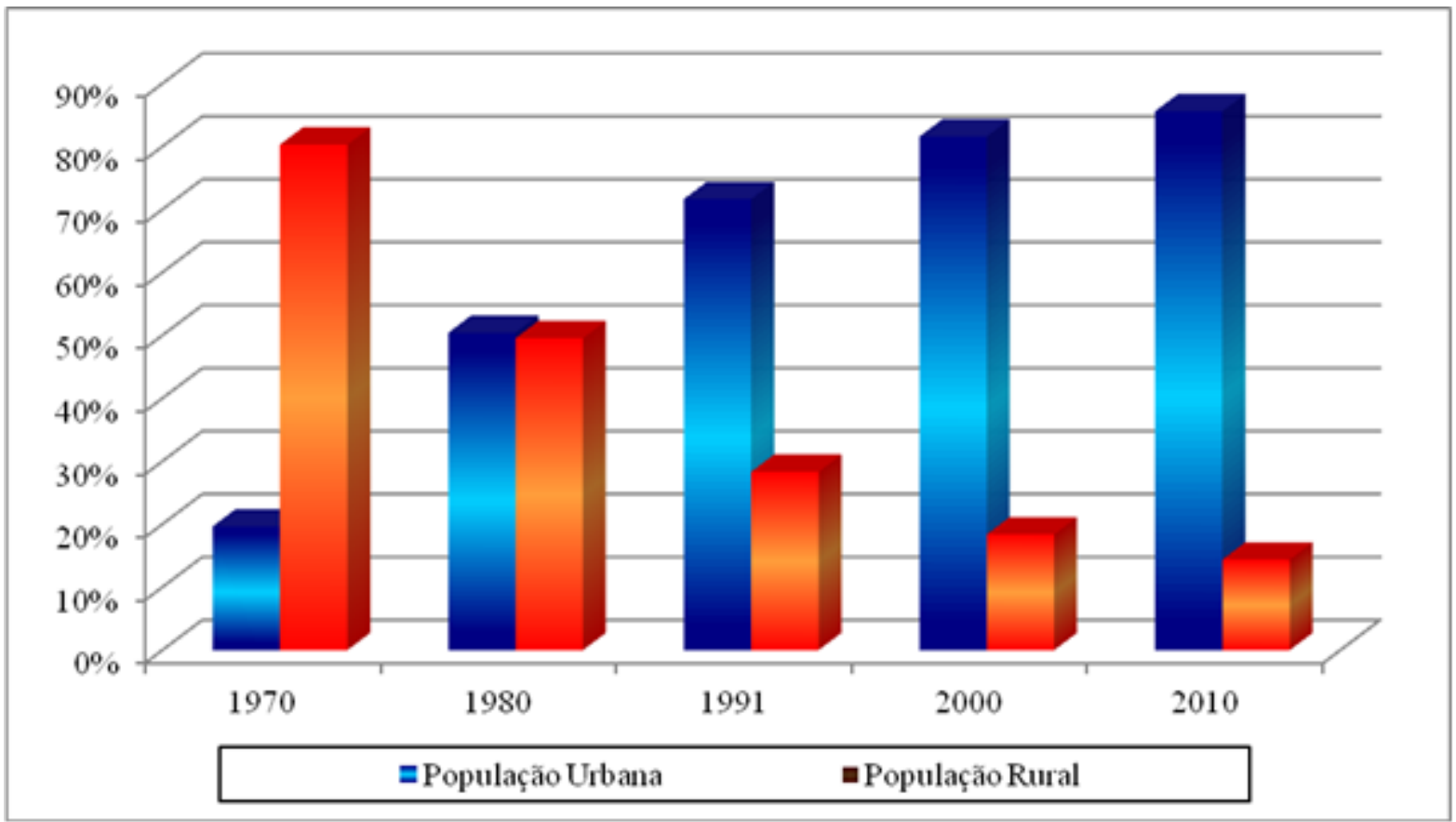

Fonte: Resultados da pesquisa a partir dos Censos Demográficos do IBGE.

No início do século XXI, os resultados do Censo Demográfico do IBGE demonstraram a nítida redução no número de municípios que contavam com uma maior concentração populacional na zona rural. Os municípios que possuíam os menores índices de população na zona rural, tanto em 2000, quanto em 2010, foram: Foz do Iguaçu, Santa Terezinha de Itaipu, Ramilândia, Diamante do Oeste, Vera Cruz do Oeste, Ouro Verde do Oeste, Ibema, Anahy e Iguatu. Com exceção de Foz do Iguaçu, os outros municípios têm uma população total de até 10 mil habitantes em domićlios rurais.

Porém, o caso de Foz do Iguaçu é atípico na Região. Em 1975, o início das obras da Usina Hidrelétrica de Itaipu capitaneou o crescimento populacional e econômico do município nas décadas seguintes. A população de Foz do Iguaçu, de 33.966 habitantes, em 1970, se expandiu para 136.321, em 1980; 190.123, em 1991; atingindo, em 2000, a marca de 258.368 habitantes (PERIS; LUGNANI, 2003).

Mesmo assim, no final do século XX, a concentração da população urbana no conjunto da Região não sofreu muitas alterações. Os municípios que concentram a maior parte da população urbana em 2000 são os mesmos de 1970, ou seja, Toledo, Cascavel, Medianeira, Foz do Iguaçu e Guaíra. Isto significa que de um lado a modernização do campo regional apresentou resultados economicamente positivos, mas de outros resultados demográficos negativos, pois a modernização rural estimulou a urbanização acelerada e o êxodo rural (RIPPEL et al., 2006). 
Neste contexto, os resultados apresentados pelos indicadores de análise regional (Figura 2) mostraram o que ocorreu com relação a distribuição da população urbana e rural, masculina e feminina, no oeste do Paraná, no inicio do século XXI. Pela Figura 2, percebe-se que, no tocante a população urbana, tanto para o gênero feminino quanto para o masculino, são basicamente os mesmos municípios que se destacam. Ou seja, Foz do Iguaçu, Medianeira, Cascavel, Toledo e Guaíra são representativos em todos os anos para os dois gêneros da população no setor urbano. Isso reflete a posição hegemônica dos polos regionais na atratividade da população de ambos os sexos.

Figura 2 Quociente Locacional para a população urbana masculina, urbana feminina, rural masculina e rural feminina por municípios do oeste paranaense, 2000/2010

QL População Urbana Masculina 2000 QL População Urbana Masculina 2010




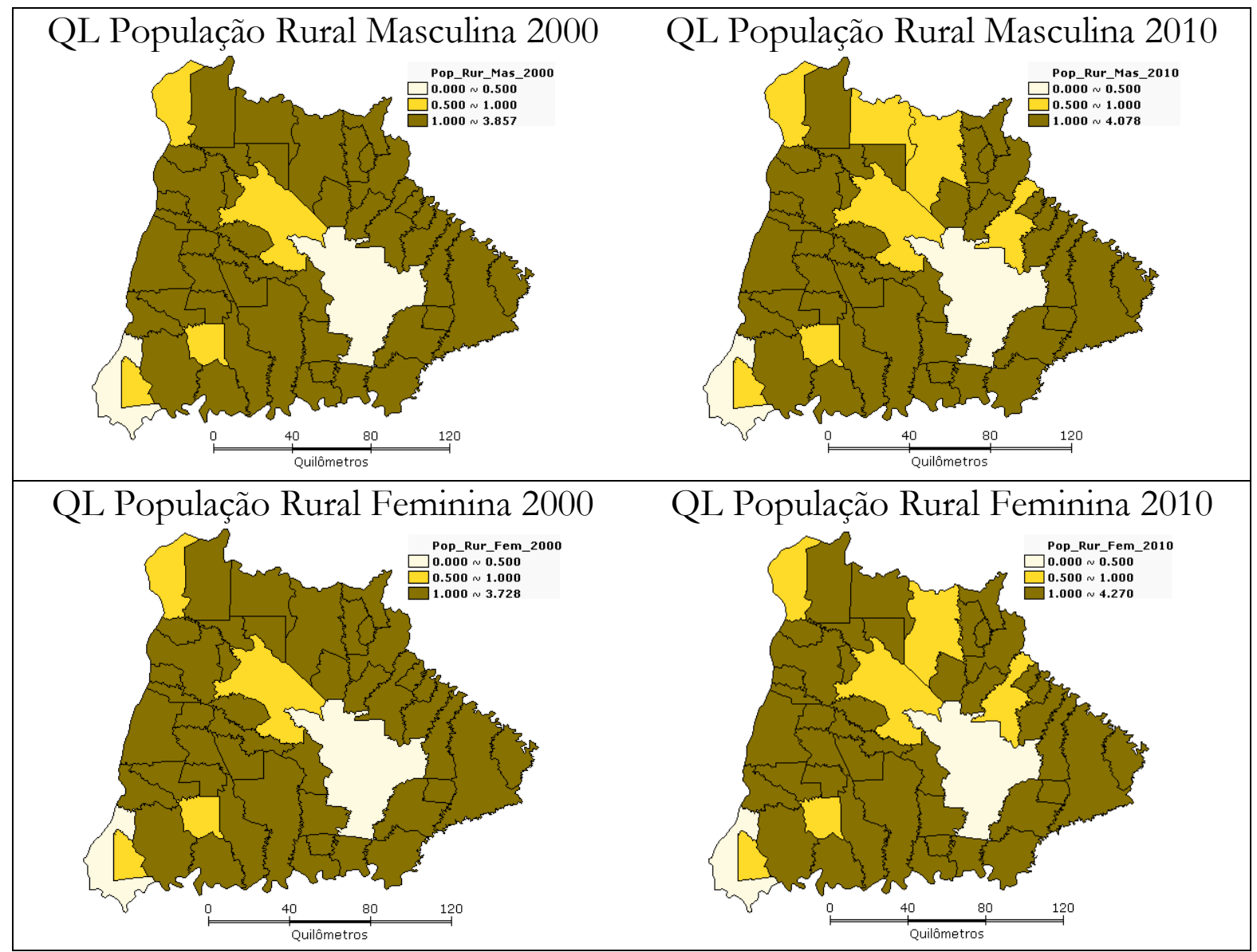

Fonte: Resultados da pesquisa a partir dos Censos Demográficos do IBGE.

Os diferenciais ocorreram para o município de Assis Chateaubriand, que se destacou no ano de 2000 e 2010 para a população urbana feminina. Palotina foi outro município que ganhou participação relativa para a população urbana masculina no ano de 2010, explicado pelo crescimento industrial que esse município obteve nesse período no setor agroalimentar.

Para os demais municípios do oeste do Paraná o que ocorre é justamente o contrário: é a população rural, tanto masculina como feminina, que ainda tem uma maior participação relativa quando se compara o conjunto da Região. Entre 2000 e 2010, alguns municípios perderam participação nesse tipo de população e são, concomitantemente, os que tiveram um ganho na participação da população urbana. Isso mostra que a Região está ganhando cada vez mais participação de atividades urbanas em suas economias, que demandam maior mobilidade e necessidade de absorção de força de trabalho. O que se reflete em um aumento relativo maior da população urbana em comparação à rural, que vem perdendo participação nas ultima décadas, como mencionado no início dessa seção.

Assim, a Figura 3 mostra os resultados do coeficiente de localização para a população rural e urbana, masculina e feminina, do oeste paranaense. 
Figura 3 - Oeste paranaense: coeficiente de localização da população rural e urbana, masculina e feminina, 2000/2010

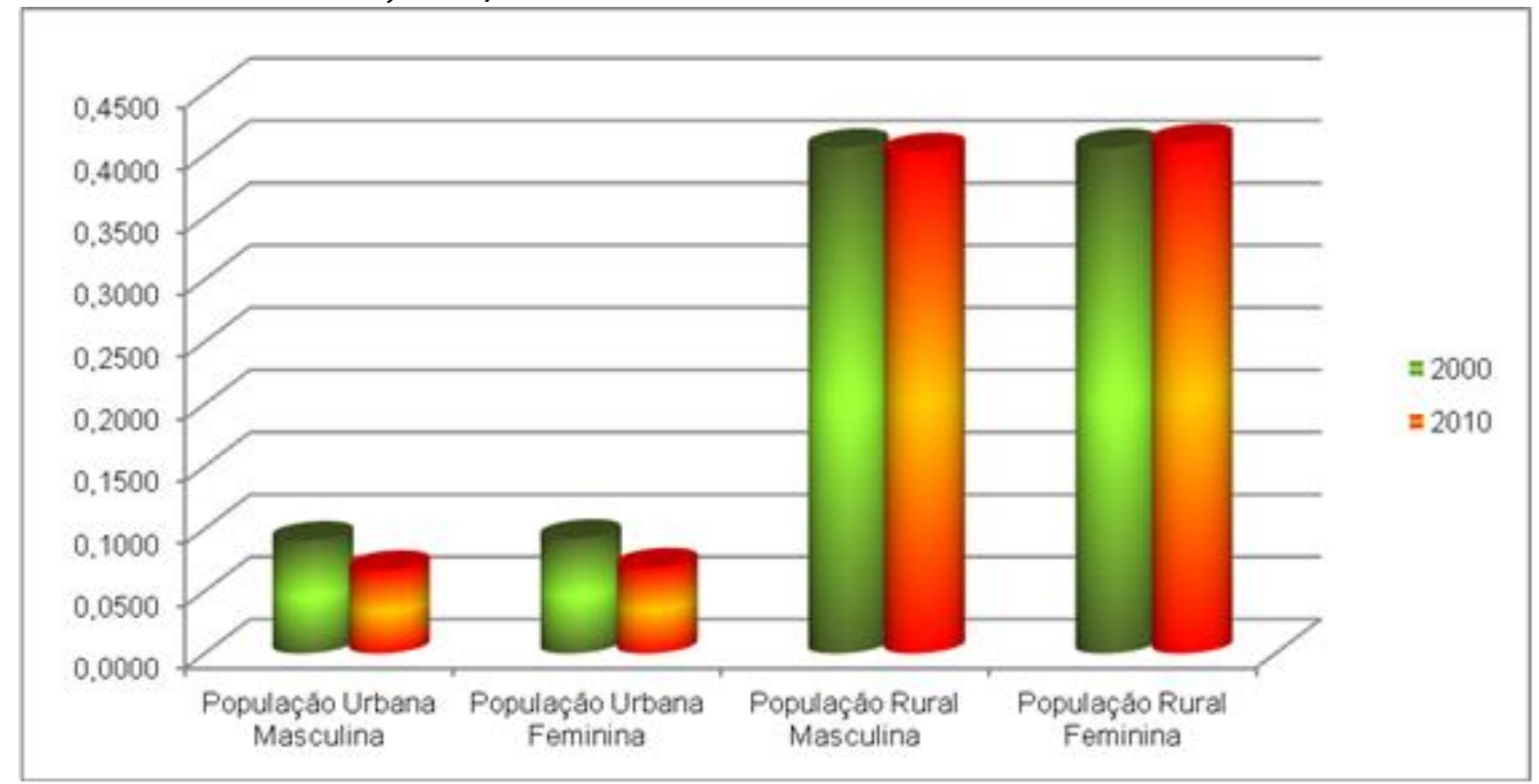

Fonte: Resultados da pesquisa a partir dos Censos Demográficos do IBGE.

A Figura 3 confirma os resultados dos QLs (Figura 2), ou seja, o aumento relativo da população urbana nos municípios do oeste do Paraná está se refletindo na maior dispersão desse tipo de população na Região. Por isso, o coeficiente de localização foi menor que o mesmo coeficiente para a população rural. Alguns municípios ainda contam com alta participação da população rural, tanto masculina quanto feminina, no total da população e isso foi confirmado por um coeficiente de localização mais elevado.

Esses resultados são complementados pelo Coeficiente de Redistribuição que é apresentado pela Figura 4. 
Figura 4 - Oeste paranaense: coeficiente de redistribuição para a população rural e urbana, masculina e feminina, 2000/2010

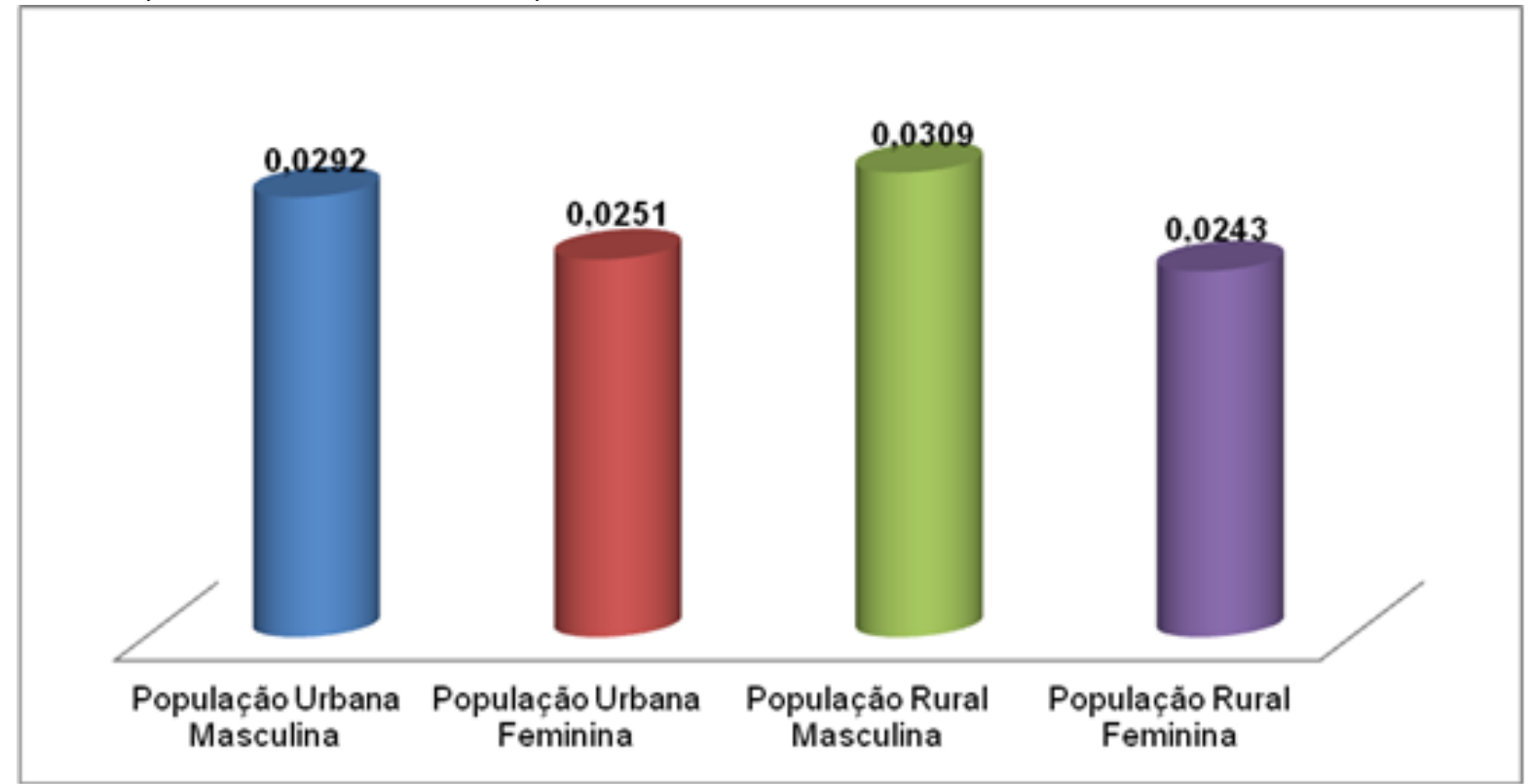

Fonte: Resultados da pesquisa a partir de dados dos Censos Demográficos do IBGE.

Os resultados da pesquisa mostraram que é a população masculina, principalmente a rural, que se dispersou mais entre os municípios do oeste do Paraná entre 2000 e 2010. Porém, é preciso ressaltar que essa dispersão foi baixa, o que se comprova pelos valores do coeficiente de redistribuição. A população feminina urbana foi a que mais se destacou na redistribuição regional. Ou seja, as áreas urbanas são cada vez mais atrativas às mulheres, o que é parcialmente explicado pelo perfil do trabalho rural, que é rude e exige força bruta em determinadas circunstâncias, o que não é inerente ao gênero feminino.

Neste contexto, a Figura 5 mostra quais foram os municípios que apresentaram mais mudanças na importância relativa de cada tipo de população no período de 2000 a 2010. 
Figura 5 - Oeste paranaense: coeficiente de reestruturação para a população rural e urbana, masculina e feminina, 2000/2010

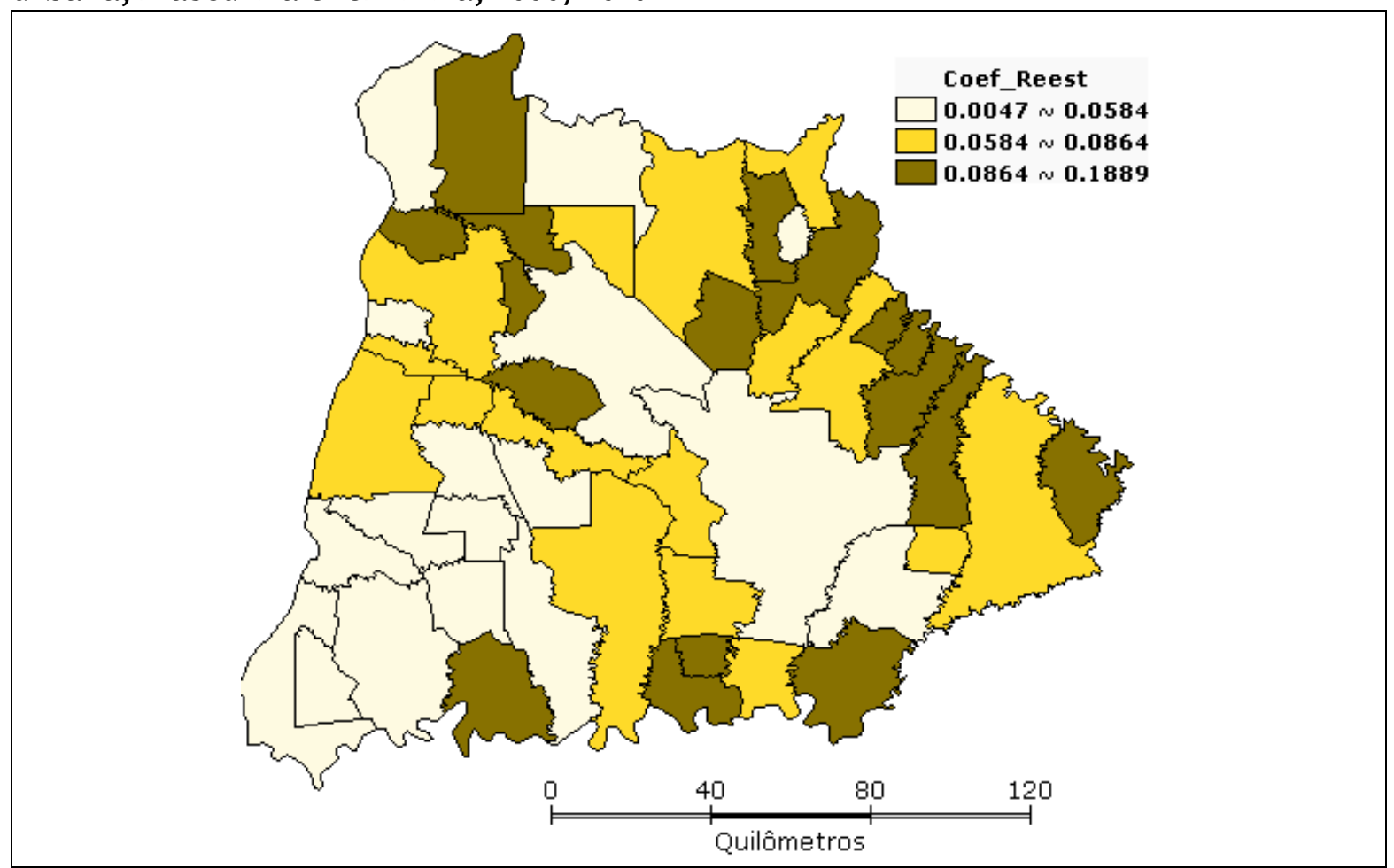

Fonte: Resultados da pesquisa a partir dos Censos Demográficos do IBGE.

A Figura 5 apresenta informações interessantes quanto ao padrão de reestruturação dos tipos de população entre os municípios do oeste do Paraná: a primeira é que os municípios com menor reestruturação no inicio do século XXI foram justamente os municípios polos regionais. Porém, em outro extremo, municípios de baixo dinamismo também se enquadraram nessa categoria, como foi o caso de Diamante D'Oeste, que apresentou menos mudanças em seu padrão de reestruturação para o período analisado. A Tabela 1 mostra informações adicionais para esse município.

Tabela 1 Participação relativa da população, por tipos, do município de Diamante D'Oeste, 2000/2010

\begin{tabular}{lccc}
\hline \multicolumn{1}{c}{ Tipos de População } & 2000 & 2010 & Diferença \\
\hline População Urbana Masculina & $25,48 \%$ & $25,10 \%$ & $-0,38 \%$ \\
População Urbana Feminina & $25,36 \%$ & $25,84 \%$ & $0,48 \%$ \\
População Rural Masculina & $26,12 \%$ & $26,02 \%$ & $-0,10 \%$ \\
População Rural Feminina & $23,04 \%$ & $23,04 \%$ & $-0,01 \%$ \\
\hline Total & $100,00 \%$ & $100,00 \%$ & - \\
\hline
\end{tabular}

Fonte: Resultados da pesquisa a partir dos Censos Demográficos do IBGE. 
No caso de Diamante D’Oeste, a participação dos tipos de população continuou muito parecida no período. Ou seja, ocorreu pequeno ganho na participação da população urbana feminina em detrimento de todos os demais.

Outro resultado interessante apresentado pelo coeficiente de reestruturação (Figura 5) é que os municípios que mais se reestruturaram estão localizados, principalmente, no entorno leste da Região e na parte mais ao sul do oeste do Paraná. O município que mais se reestruturou foi Anahy. A Tabela 2 mostra com mais detalhes o que ocorreu com esse município.

Tabela 2 Participação relativa da população, por tipos, do município de Anahy, $2000 / 2010$

\begin{tabular}{lccc}
\hline \multicolumn{1}{c}{ Tipos de População } & 2000 & 2010 & Diferença \\
\hline População Urbana Masculina & $27,23 \%$ & $35,73 \%$ & $8,50 \%$ \\
População Urbana Feminina & $27,23 \%$ & $37,61 \%$ & $10,38 \%$ \\
População Rural Masculina & $23,81 \%$ & $14,34 \%$ & $-9,48 \%$ \\
População Rural Feminina & $21,72 \%$ & $12,32 \%$ & $-9,40 \%$ \\
\hline Total & $100,00 \%$ & $100,00 \%$ & - \\
\hline
\end{tabular}

Fonte: Resultados da pesquisa a partir dos Censos Demográficos do IBGE.

Percebe-se que Anahy perdeu bastante população rural no inicio do século XXI, fazendo com que a participação relativa desse tipo de população diminuísse consideravelmente no período. A população urbana feminina foi a que mais ganhou nessa reestruturação. Cabe ressaltar ainda que a porção leste da região oeste do Paraná, tomando Cascavel (município polo) como limite geográfico e divisor, apresenta os indicadores de desenvolvimento humano menos expressivos no contexto regional. A reestruturação da população reflete-se então em arranjos tanto na questão de localização do capital humano, quanto dos movimentos migratórios que a falta de oportunidades estimula. O caso de Anahy é expressivo nesse sentido, pois a retração da população rural não foi compensada pela absorção das áreas urbanas, demonstrando que um contingente significativo de habitantes tem deixado o município.

\section{Conclusão}

A região oeste do Paraná foi ocupada e colonizada efetivamente no século XX. Uma colonização marcada pela exploração extrativista de madeira e, na sequência, pela agricultura e pela pecuária. A Região se integra à dinâmica da economia nacional somente a partir de 1950, com o assentamento de imigrantes, a produção de excedentes comercializáveis e a implantação de modais de transporte integrando o oeste do Paraná ao restante do Brasil. Com a modernização da 
agricultura ocorrida a partir de 1960, a Região encerra o ciclo de ocupação e entra numa nova fase econômica: a reestruturação da base produtiva. Essa reestruturação, que marcará os anos 1970 e 1980, foi estimulada pela modernização da base técnica de produção agropecuária, o aumento da produtividade da agropecuária regional, a ocupação intensiva do espaço regional e as grandes obras de infraestrutura (usinas hidroelétricas e estradas). O resultado econômico foi o fortalecimento da economia e o social foi a urbanização acelerada pelo êxodo rural.

Apesar de a Região ser formada por cinquenta municípios, a polarização e concentração expressiva do Produto Interno Bruto (PIB) regional em três municípios polos (Toledo, Cascavel e Foz do Iguaçu) marcam o contexto regional. Os municípios de Toledo e Cascavel, com suas economias dinamizadas pelas atividades de transformação e o fortalecimento do setor terciário, polarizam cada vez mais os municípios do seu entorno. Já Foz do Iguaçu mantém sua economia urbana dinâmica fortalecida no comércio inter-regional, na produção de energia e no turismo.

A realidade da região oeste modificou-se tanto nas últimas três décadas do século XX que se formaram três territorialidades econômicas no seu espaço: há o território econômico dos municípios com um continuum urbano industrial consolidado, que marca os municípios polos (os mais urbanizados da Região); o território econômico dos municípios em transição de um continuum urbano rural para urbano industrial (que ganham cada vez mais contingente populacional urbano); e o território econômico dos municípios retardatários, com um continuum exclusivamente urbano rural, ou seja, a periferia regional que apenas fornece insumos para os municípios polos ou em transição.

Nesse contexto, haja visto que há um grande corredor de desenvolvimento no oeste paranaense, capitaneado por um conjunto de doze municípios, o padrão locacional da população por gênero fornecerá um sistema de informações sobre as tendências de localização da mão de obra masculina e feminina, fornecendo elementos para políticas públicas de qualificação de mão de obra e de inclusão social nessa região.

Os resultados desse artigo mostraram que os três municípios polos consolidaramse com um perfil de população urbana masculina e feminina mais intensa que os demais municípios da região. Junto com Cascavel, Foz do Iguaçu e Toledo, destacaram-se nessa condição os municípios de Santa Terezinha de Itaipu, Medianeira e Guaíra na população urbana masculina. Ainda com relação a esse gênero, em 2010, os municípios de Palotina, Assis Chateaubriand e Cafelândia aumentaram suas representatividades da população urbana. A análise da população urbana feminina mostrou que, com exceção de Cafelândia, todos os demais municípios que se destacavam na população urbana masculina também se 
destacavam na população urbana feminina. Nesse gênero da população também se destacou no mesmo período o município de Corbélia.

Os municípios periféricos estão consolidando suas economias na transformação agroalimentar através de cooperativas de produção ou na prestação de serviços, fato que se reflete em uma maior participação da população. Por outro lado, todos os demais municípios que não apresentaram quocientes locacionais significativos para os gêneros da população urbana, o apresentaram para a população rural, também para os dois gêneros.

Dessa forma, fica evidente que as políticas públicas de qualificação de mão de obra e de inclusão social devem levar em consideração o crescimento da população urbana nessa região, com destaque para os municípios que têm apresentado crescimentos maiores. A qualificação da mão de obra deve privilegiar os segmentos econômicos que ganham força nas atividades urbanas (industrial, serviços e comércio) nos municípios do oeste do Paraná.

\section{Referências}

CUNHA, J. M. P. et al. Diagnósticos regionais do Estado do Mato Grosso. Campinas: Núcleo de Estudos de População/UNICAMP, 2004. 225p. (Diagnósticos regionais do Estado do Mato Grosso, TEXTOS NEPO 49).

A redistribuição espacial da população: tendências e trajetória. Revista São Paulo em Perspectiva, Fundação SEADE/SP. v. 17, n. 3-4, jul./dez. 2003.

DELGADO, A. P.; GODINHO, I. M. Medidas de localização das actividades e de especialização regional. In: COSTA, J. S. (Coord.). Compêndio de economia regional. Lisboa: APDR, 2002. p. 723-742.

IBGE. Instituto Brasileiro de Geografia e Estatística. Sistema IBGE de recuperação automática. Disponível em: <http://www.sidra.ibge.gov.br>. Acesso em: 03 jul. 2012.

PERIS, A. F.; LUGNANI, A. C. Um estudo sobre o eixo Cascavel-Foz do Iguaçu na Região Oeste do Paraná. Revista Paranaense de Desenvolvimento, Curitiba: Ipardes, n. 104, p. 79-102, 2003.

PIACENTI, C. A.; FERRERA DE LIMA, J. (Orgs.). Análise regional: indicadores e metodologias. Curitiba: Camões, 2012. 
PIFFER, M. Apontamentos sobre a base econômica da Região Oeste do Paraná. In: CASSIMIRO FILHO, F.; SHIKIDA, P. F. A. (Orgs.). Agronegócio e desenvolvimento regional. Cascavel: EDUNIOESTE, 1999. p. 57-84.

PUMAIN, D; SAINT-JULIEN, T. L'analyse spatiale: localizations dans l'espace. Paris: Armand Colin, 1997.

RIPPEL, R. Migração e desenvolvimento econômico no Oeste do Estado do Paraná: uma análise de 1950 a 2000. Tese (Doutorado em Demografia) Instituto de Filosofia e Ciências Humanas da UNICAMP - Universidade Estadual de Campinas, Campinas, 2005.

RIPPEL, R.; FERRERA DE LIMA, J.; ALVES, L. R., PIACENTI, C., A. Notas sobre a localização da população urbana e rural no Oeste paranaense. In: Encontro Nacional de Estudos Populacionais (ABEP), XV., 2006, Caxambu/MG. Anais... Caxambu: ABEP, 2006. Disponível em: <http://www.abep.nepo. unicamp.br/encontro2006/docspdf/ABEP2006_445.pdf $>$. Acesso em: 11 abr. 2012.

Endereço para correspondência:

Lucir Reinaldo_Alves - lucir.alves@unioeste.br

Rua da Faculdade, 645, Curso de Ciências Econômicas

85903-000 Toledo/PR, Brasil

Jandir Ferrera de Lima - jandir.lima@unioeste.br

Rua da Faculdade, 645, PGDRA

85903-000 Toledo/PR, Brasil

Ricardo Rippel-ricardo.rippel@unioeste.br

Rua da Faculdade, 645, PGDRA

85903-000 Toledo/PR, Brasil

MoacirPiffer-moacir.piffer@unioeste.br

Rua da Faculdade, 645, PGDRA

85903-000 Toledo/PR, Brasil 